\title{
Evaluasi Kesesuaian Jadwal Pemeliharaan Runway dengan Pertumbuhan Pergerakan Pesawat di Bandar Udara Juanda
}

\author{
Freedy Kristiawan, Ervina Ahyudanari, Istiar \\ Lintas Jalur Departemen Teknik Sipil, Fakultas Teknik Sipil dan Perencanaan, Institut Teknologi \\ Sepuluh Nopember \\ E-mail: ervina@ce.its.ac.id
}

\begin{abstract}
Abstrak - Bandar udara Juanda menempati urutan kedua sebagai bandar udara tersibuk di Indonesia dengan data statistic jumlah penumpang yang mampu ditampung adalah 18 juta penumpang pada tahun 2015. Berdasarkan data kondisi saat ini dari PT Angkasa Pura I, pertumbuhan jumlah penumpang di bandar udara (bandara) Juanda pada triwulan I 2016 tercatat lebih besar 23.4\% dibandingkan dengan periode yang sama tahun lalu. Pertumbuhan ini mengakibatkan kerusakan yang terjadi pada runway semakin sering terjadi. Kerusakan yang terjadi biasanya hanya bersifat fungsional sehingga perbaikan yang dilakukan cukup dengan dilakukan pelapisan ulang (overlay) dan pemeliharaan lainnya. Permasalahan utama yang terjadi yaitu kesesuaian jadwal pemeliharaan dan pelapisan ulang terhadap pertumbuhan pergerakan pesawat. Pada studi ini dilakukan evaluasi kesesuaian antara jadwal pemeliharaan dengan pertumbuhan pergerakan pesawat. Tahap evaluasi dimulai dengan penyesuaian pola pertumbuhan pergerakan pesawat dengan kondisi perkerasan runway. Selanjutnya dilakukan jadwal pemeliharaan sesuai pola yang diterapkan oleh pihak bandara Juanda. Di samping itu, dilakukan perencanaan kebutuhan tebal pelapisan ulang yang dibutuhkan runway agar dapat melayani pertumbuhan pergerakan pesawat yang terjadi. Dalam evaluasi ini juga dibahas tentang pemeliharaan runway terhadap kontaminasi rubber deposit serta kesesuaian jadwal pemeliharaannya. Evaluasi dalam studi ini memberikan hasil untuk pertumbuhan pergerakan pesawat rata-rata total dalam 8 tahun terakhir (2009-2016) adalah $6.93 \%, \quad 7.33 \%$ untuk penerbangan domestik dan $4.14 \%$ untuk penerbangan internasional. Peratingan kondisi perkerasan runway berdasarkan pengecekan visual maka dikategorikan rating 3 (fair) dimana dalam rating ini diperlukan tindakan pemeliharaan berupa overlay. Pemeliharaan kerusakan-kerusakan kecil masih mempertahankan pemeliharaan langsung seperti yang dilakukan pihak bandara Juanda. Adapun untuk kegiatan overlay yaitu dilakukan perataan dengan ketebalan menyesuaikan dengan tebal perkerasan tertinggi sebesar $1299 \mathrm{~mm}$ terhadap semua segmen. Untuk mencapai usia perencanaan hingga 20 tahun, perlu dilakukan pemeliharaan setiap 5 tahun dan pengawalan intensif agar usia pemeliharaan minimum dan usia rencana maksimum dapat terlaksana dengan baik.
\end{abstract}

Kata Kunci-Overlay, runway, Juanda, Pemeliharaan.

\section{PENDAHULUAN}

\section{A. Latar Belakang}

$\mathrm{B}$ ANDAR udara Juanda menempati urutan kedua dengan data statistik untuk jumlah penumpang yang mampu ditampung adalah 18 juta penumpang pada tahun 2015. Data kondisi saat ini dari PT Angkasa Pura I bandar udara Juanda mencatat pertumbuhan jumlah penumpang sebesar $23,4 \%$ di triwulan I 2016 dibandingkan dengan periode yang sama tahun lalu [1].

Menyandang predikat sebagai salah satu bandara tersibuk di negeri ini menyebabkan timbulnya berbagai macam permasalahan diantaranya menurunnya kemampuan lapisan permukaan runway dalam melayani beban dari pesawat. Kondisi saat ini yang dialami bandara dengan pesatnya pertumbuhan lalu lintas udara di Indonesia dengan rata-rata pertumbuhan dalam 5 tahun terakhir mencapai angka 7,6\% per tahunnya [2], mengakibatkan adanya pengulangan beban lalu lintas yang tinggi oleh pesawat dan menyebabkan sistem perkerasan menjadi lelah atau fatigue [3]. Tingginya pergerakan penerbangan yang tidak diikuti dengan pemeliharaan fungsional perkerasan landasan akan memperpendek umur landasan [3]

Guna mengatasi permasalahan perkerasan yang dihadapi terdapat beberapa pilihan jenis perkerasan yang dapat diterapkan mengacu kepada mekanisme distribusi tegangan yang diterima. Macam-macam jenis perkerasan yang dapat digunakan antara lain:

1. Rigid Pavement atau perkerasan kaku terbuat dari beton semen portland dan menggunakan pengaku plat beton.

2. Flexible Pavement biasanya dibangun menggunkan produk bituminus dan jenis perkerasan ini tergantung pada daya dukung struktur lapisannya.

Overlay merupakan lapis perkerasan tambahan yang dipasang di atas konstruksi perkerasan yang ada dengan dengan tujuan meningkatkan kekuatan struktur perkerasan yang ada agar dapat melayani lalu lintas yang direncanakan selama kurun waktu yang akan dating.

Dalam memperbaiki kerusakan serta memenuhi kebutuhan tebal perkerasan runway di Bandar udara Juanda dipilih metode overlay dengan melakukan penambahan lapisan runway.

Kebutuhan penambahan tebal lapisan struktur perkerasan runway tergantung pada pergerakan pesawat, dimana pada setiap tahunnya selalu ada peningkatan yang cukup signifikan pada bandar udara Juanda ini. Oleh karena itu dilakukan penghitungan pada setiap pesawat yang melakukan keberangkatan dalam kurun waktu satu tahunan. Dengan dilakukan penghitungan ini maka akan didapat data keberangkatan tahunan untuk semua jenis pesawat yang dapat digunakan untuk mendesain kebutuhan penambahan tebal lapisan struktur perkerasan. 
Padatnya aktifitas lalu lintas di bandar udara Juanda ini menyebabkan pekerjaan overlay untuk bandara ini tidak dapat selalu dilakukan dikarenakan kegiatan overlay yang dikerjakan pada sisi runway dapat menghambat kegiatan operasional bandar udara Juanda. Adanya hambatan pada operasional bandar udara ini dapat menyebabkan kerugian yang besar untuk pihak bandar udara sendiri, pihak maskapai penerbangan, dan juga para penumpang. Oleh karena itu frekuensi pekerjaan overlay harus direncanakan dengan baik agar kegiatan ini dapat dilakukan secara efisien dan tidak terlalu sering mengganggu kegiatan operasional dari bandar udara Juanda.

Dengan adanya kondisi seperti yang telah disebutkan diatas, maka diperlukan adanya evaluasi terhadap kesesuaian pertumbuhan pesawat dengan frekuensi pekerjaan overlay yang dilakukan di bandar udara Juanda. Tujuan dari kegiatan evaluasi ini adalah untuk mengetahui apakah kegiatan overlay yang selama ini dilakukan di bandar udara Juanda sudah sesuai dengan kebutuhan secara struktural atau belum.

\section{B. Tujuan}

Tujuan yang ingin didapat dari pembahasan studi ini diuraikan sebagai berikut:

1) Mengetahui pertumbuhan pergerakan pesawat terbang dari tahun ke tahun.

2) Mengetahui kondisi perkerasan runway dengan sistem peratingan agar dapat ditentukan untuk upaya pemeliharaanya.

3) Menentukan tebal perkerasan yang dibuthkan pada runway untuk melayani lalu lintas pesawat dalam beberapa tahun kedepan.

4) Mengevaluasi jadwal kegiatan pemeliharaan yang dilakukan di runway.

\section{Batasan Masalah}

Dalam penyusunan studi ini diberikan beberapa batasan masalah sebagai berikut :

- Tidak membahas kinerja terminal yang ada di bandar udara Juanda.

- Tidak membahas drainase terkait.

- Tidak membahas perbaikan tanah.

- Hanya membahas sisi runway bandar udara Juanda.

- Hasil peramalan jumlah pergerakan pesawat hanya untuk pengisian data saja.

\section{Diagram Alir}

Di bawah ini adalah gambar diagram alir metodologi penelitian.

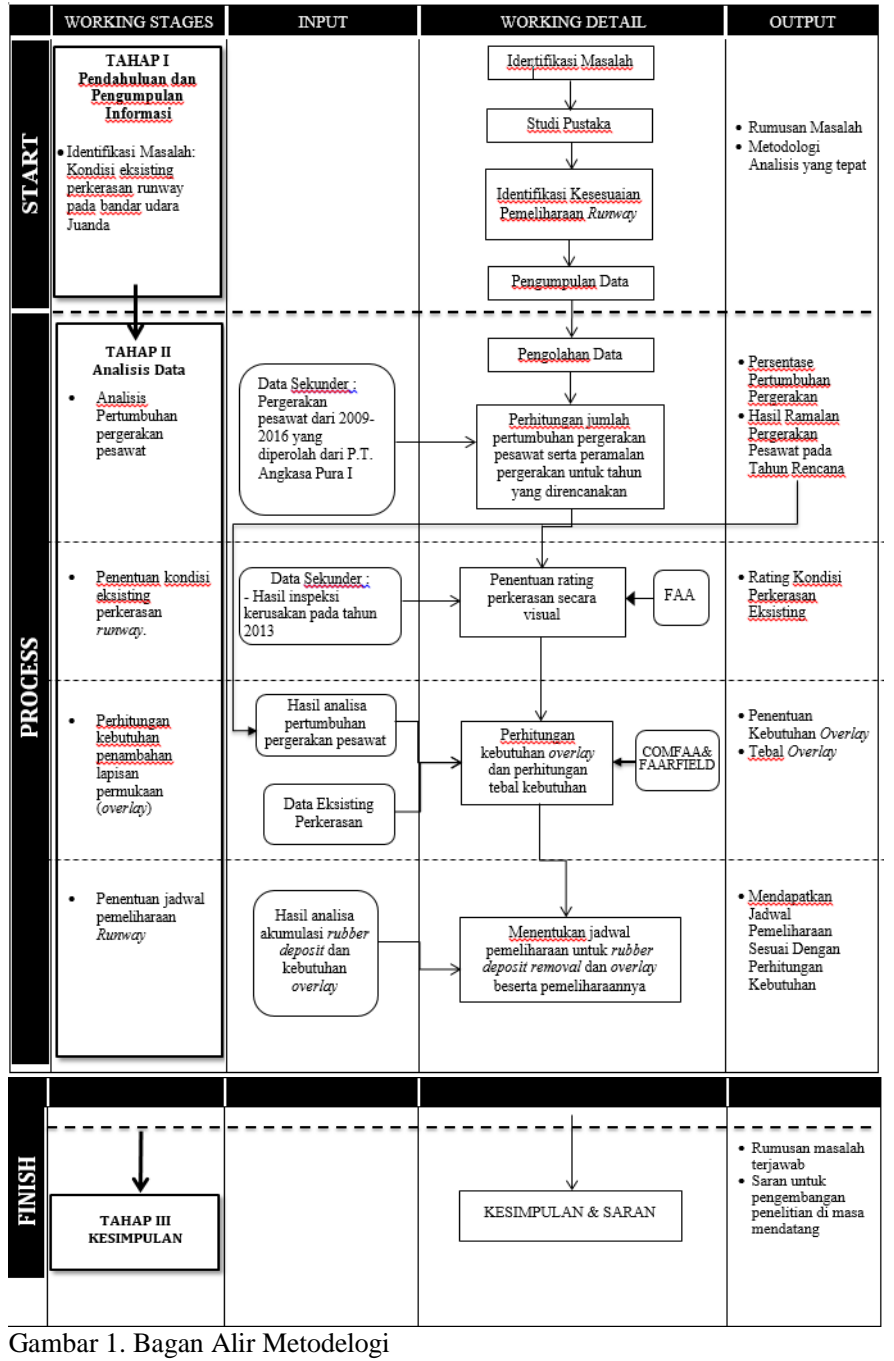

\section{HASIL ANALISIS DATA DAN PEMBAHASAN}

\section{A. Analisis Runway}

Data umum dan teknis untuk kondisi runway bandara juanda dapat dilihat pada tabel dibawah ini.

Tabel 1.

Data teknis Runway Bandara Juanda

\begin{tabular}{ccc}
\hline & \multicolumn{2}{c}{ Data teknis Runway Bandara Juanda } \\
\hline No & Detail & Keterangan \\
\hline 1 & Nama & R10/R28 \\
2 & Panjang & $3000 \mathrm{~m}$ \\
3 & Lebar & $45 \mathrm{~m}$ \\
4 & Elevasi tertinggi & \\
& R10 & $11 \mathrm{Feet}$ \\
& R28 & 8 Feet \\
5 & Temperatur & $27^{\circ}-32^{\circ} \mathrm{C}$ \\
6 & Lapis permukaan & Asphalt Concrete \\
7 & Kode Perkerasan & PCN 83 F/D $/ \mathrm{X} / \mathrm{T}$ \\
\hline
\end{tabular}

Adapun data teknis kondisi perkerasan runway dapat dilhat pada gambar dibawah ini. 


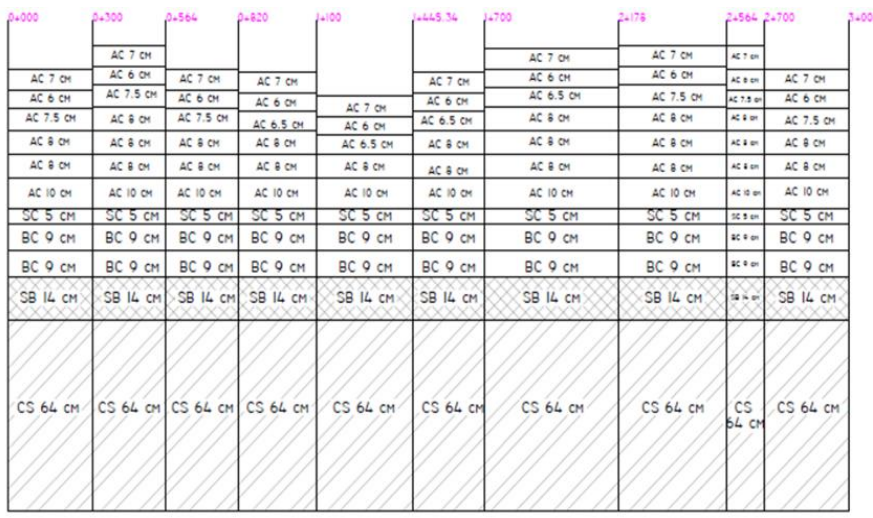

Gambar 2. Kondisi eksisting dan pavement historis runway

Hasil analisis kondisi eksisting runway dapat dilhat pada tabel dibawah ini.

Tabel 2.

\begin{tabular}{crrr}
\multicolumn{4}{c}{ Analisis tebal perkerasan eksisting } \\
\hline \hline & \multicolumn{1}{c}{ Segmentasi } & \multicolumn{2}{c}{ Ketebalan } \\
Segmen & \multicolumn{1}{c}{ STA } & Panjang & Eksisting (mm) \\
\hline 1 & $0+300$ & 300 & 1219 \\
2 & $0+300-0+564$ & 264 & 1219 \\
3 & $0+564-0+820$ & 256 & 1219 \\
4 & $0+820-1+100$ & 280 & 1209 \\
5 & $1+100-1+445,34$ & 345,34 & 1129 \\
6 & $1+445,34-1+700$ & 254,66 & 1209 \\
7 & $1+700-2+178$ & 478 & 1289 \\
8 & $2+178-2+564$ & 386 & 1299 \\
9 & $2+564-2+700$ & 136 & 1299 \\
10 & $2+700-3+000$ & 300 & 1219 \\
\hline \hline
\end{tabular}

Analisis runway juga dilakukan terhadap kerusakankerusakan yang terjadi di runway. Kerusakan ini berdasarkan hasil inspeksi oleh P.T. Angkasa Pura I bandar udara Juanda. Dari hasil inspeksi kemudian dilakukan analaisis terhadap penyebab dan upaya penanganan kerusakan tersebut [4]. Dari analisis penyebab kerusakan dikategorikan menjadi 3 macam.

1. Kerusakan akibat pengulangan beban lalu lintas. Macam-macam jenis kerusakan dan upaya penanganan dapat dilihat pada tabel dibawah ini. Tabel 3.

Kerusakan akibat pengulangan beban lalu lintas

\begin{tabular}{|c|c|c|c|c|}
\hline \multirow[b]{2}{*}{ No } & \multirow{2}{*}{ Jenis Kerusakan } & \multicolumn{3}{|c|}{ Penanganan Menurut Kondisi } \\
\hline & & Ringan & Sedang & Berat \\
\hline \multirow[b]{2}{*}{1} & & Jika Lebar $\leq 3 \mathrm{~mm}$ & $3 \mathrm{~mm} \leq$ Lebar Crack $\leq 2 \mathrm{~cm}$ & $2 \leq$ Lebar Crack \\
\hline & Aligator Crack & $\begin{array}{l}\text { Ditutup dengan aspal emulsi } \\
\text { sesuai spesifikasi }\end{array}$ & $\begin{array}{l}\text { Bagian dipotong dan dilapis } \\
\text { kembali dengan material sesuai } \\
\text { spesifikasi }\end{array}$ & \begin{tabular}{|l|} 
Patching lokal, diisi \\
Asphalt concrete (AC) \\
kemudian di overlay
\end{tabular} \\
\hline \multirow[b]{2}{*}{2} & & Jika Lebar $\leq 3 \mathrm{~mm}$ & $3 \mathrm{~mm} \leq$ Lebar Crack $\leq 2 \mathrm{~cm}$ & $2 \leq$ Lebar Crack \\
\hline & Block Crack & $\begin{array}{l}\text { Mentutup retakan dengan } \\
\text { bahan pengisi }\end{array}$ & $\begin{array}{l}\text { Ditutup dengan aspal emulsi dan } \\
\text { campuran Asphalt concrete } \\
\text { (AC) }\end{array}$ & \begin{tabular}{|l|} 
Patching lokal, \\
kemudian disi Asphalt \\
concrete (AC)
\end{tabular} \\
\hline \multirow[b]{2}{*}{3} & & $\leq 8 \mathrm{~mm}$, tanpa retakan & $\leq 25 \mathrm{~mm}$, tanpa retakan & $>25 \mathrm{~mm}$, tanpa retakan \\
\hline & Rutting & \begin{tabular}{|l} 
Pengamatan lebih untuk \\
tinjauan air di area rutting
\end{tabular} & $\begin{array}{l}\text { Patching lokal, kemudian disi } \\
\text { Asphalt concrete (AC) }\end{array}$ & \begin{tabular}{|l|} 
Patching lokal, \\
kemudian disi Asphalt \\
concrete (AC)
\end{tabular} \\
\hline
\end{tabular}

2. Kerusakan akibat pengaruh suhu.

Macam-macam jenis kerusakan dan upaya penanganan dapat dilihat pada tabel dibawah ini.
Tabel 4.

Kerusakan akibat pengaruh suhu

\begin{tabular}{|c|c|c|c|c|}
\hline \multirow[b]{2}{*}{ Noo } & \multirow{2}{*}{ Jenis Kerusakan } & \multicolumn{3}{|c|}{ Penanganan Menurut Kondisi } \\
\hline & & Ringan & Sedang & Berat \\
\hline & \begin{tabular}{|l} 
Retak memanjang \\
$\&$ melintang
\end{tabular} & Pengisian dengan aspal & $\begin{array}{l}\text { Patching lokal, kemudian diisi } \\
\text { Asphalt Concrete (AC) }\end{array}$ & $\begin{array}{l}\text { Patching lokal, disi Asphalt } \\
\text { Concrete (AC) kemudian di } \\
\text { overlay }\end{array}$ \\
\hline 2 & Slippage Crack & $\begin{array}{l}\text { Patching lokal, kemt } \\
\text { Asphalt Concrete } \\
\end{array}$ & $\begin{array}{l}\text { Ditutup dengan aspal emulsi dan } \\
\text { campuran Asphalt Concrete (AC) }\end{array}$ & \begin{tabular}{|l|}
$\begin{array}{l}\text { Patching lokal, kemudian diisi } \\
\text { Asphalt Concrete (AC) }\end{array}$ \\
\end{tabular} \\
\hline r & Raveling & Pembersihan dan Pengamatan & $\begin{array}{l}\text { Patching lokal, kemudian disi } \\
\text { Asphalt Concrete (AC) }\end{array}$ & $\begin{array}{l}\text { Patching lokal, kemudian disi } \\
\text { Asphalt Concrete (AC) }\end{array}$ \\
\hline & Pothole & $\begin{array}{l}\text { Patching lokal, kemudian diisi } \\
\text { Asphalt Concrete (AC) } \\
\end{array}$ & $\begin{array}{l}\text { Patching lokal, kemudian diisi } \\
\text { Asphalt Concrete (AC) }\end{array}$ & \begin{tabular}{|l|} 
Patching lokal, kemudian diisi \\
Asphalt Concrete (AC)
\end{tabular} \\
\hline & Asphalt Stripping & $\begin{array}{l}\text { Patching lokal, kemudian diisi } \\
\text { Asphalt Concrete (AC) }\end{array}$ & $\begin{array}{l}\text { Patching lokal, kemudian diisi } \\
\text { Asphalt Concrete (AC) }\end{array}$ & $\begin{array}{l}\text { Patching lokal, kemudian diisi } \\
\text { Asphalt Concrete (AC) }\end{array}$ \\
\hline f & Erosi Jetblast & Pembersihan dan Pengamatan & $\begin{array}{l}\text { Patching lokal, kemudian diisi } \\
\text { Asphalt Concrete (AC) }\end{array}$ & \begin{tabular}{|} 
Patching lokal, kemudian diisi \\
Asphalt Concrete (AC)
\end{tabular} \\
\hline
\end{tabular}

3. Kerusakan akibat pengaruh friksi.

Macam-macam jenis kerusakan dan upaya penanganan dapat dilihat pada tabel dibawah ini.

Tabel 5.

Kerusakan akibat pengaruh friksi

\begin{tabular}{|c|c|c|}
\hline No & Jenis Kerusakan & Penanganan \\
\hline 1 & $\begin{array}{l}\text { Agregat Aus (akibat } \\
\text { airtraffic) }\end{array}$ & $\begin{array}{l}\text { Patching lokal, \& diisi } \\
\text { Asphalt Concrete }\end{array}$ \\
\hline 2 & $\begin{array}{l}\text { Kontaminasi (tumpahan } \\
\text { bahan bakar,oli, dll) }\end{array}$ & $\begin{array}{l}\text { Patching lokal, \& diisi } \\
\text { Asphalt Concrete }\end{array}$ \\
\hline 3 & Rubber Deposit & Rubber Deposit Removal \\
\hline 4 & $\begin{array}{l}\text { Keluarnya material aspal ke } \\
\text { permukaan }\end{array}$ & $\begin{array}{l}\text { Patching lokal, \& diisi } \\
\text { Asphalt Concrete }\end{array}$ \\
\hline
\end{tabular}

Selanjutnya diadakan upaya penentuan rating kondisi runway berdasarkan hasil kerusakan yang dapat dilihat secara visual. Dari data inspeksi yang diterima kondisi perkerasan runway masuk kedalam kondisi rating 3 (fair) dan membutuhkan penanganan berupa pemeliharaan pada lapis permukaan. Penentuan rating kondisi didasarkan pada beberapa point berikut ini [3].

1) Moderate Raveling.

2) Thermal crack \& joint crack less than 50' $(1,27 \mathrm{~m})$

3) Dibukan kegiatan perbaikan berupa penyegelan.

4) Terjadi keretakan disertai dengan penurunan.

5) Serta terjadi jenis kerusakan lainnya.

\section{B. Analisis Pertumbuhan Pergerakan Pesawat.}

Dalam studi ini data lalu lintas yang diperoleh dari PT. Angkasa Pura I Bandara Juanda Surabaya adalah data lalu lintas pergerakan pesawat setiap bulan pada tahun 2012 sampai tahun 2016 [4]. Data yang diperoleh digunakan untuk mengetahui pertumbuhan pergerakan pesawat dalam kurun waktu tersebut.

Dari data yang diperoleh, maka dapat dihitung persentase pertumbuhan pergerakan pesawat dengan cara berikut:

Persentase $=\frac{(P 2-P 1)}{P 1} \times 100 \%$

Contoh perhitungan persentase pertumbuhan pergerakan pesawat domestik dari tahun 2009-2010 adalah sebagai berikut:

$$
\begin{gathered}
\text { Persentase }=\frac{(P 2-P 1)}{P 1} \times 100 \%=\frac{(93.149-84.211)}{84.211} \times 100 \% \\
\text { Persentase }=10,61 \%
\end{gathered}
$$

Hasil dari perhitungan pergerakan pesawat baik internasional dan domestik dapat dilihat pada Tabel 6 untuk persentase pertumbuhan pesawat total yang menggunakan bandara udara Juanda, serta Tabel 7 untuk persentase pertumbuhan pergerakan 
pesawat yang ditinjau berdasarkan keberangkatan internasional dan domestik.

Tabel 6.

Persentase pertumbuhan pergerakan pertahun

\begin{tabular}{rrrr}
\hline \hline No & Tahun & Total Pergerakan & \% Pertumbuhan \\
\hline 1 & 2009 & 94.066 & - \\
2 & 2010 & 102.187 & $8,63 \%$ \\
3 & 2011 & 116.765 & $14,27 \%$ \\
4 & 2012 & 134.824 & $15,47 \%$ \\
5 & 2013 & 139.698 & $3,62 \%$ \\
6 & 2014 & 136.195 & $-2,51 \%$ \\
7 & 2015 & 137.051 & $0,63 \%$ \\
8 & 2016 & 148.602 & $8,43 \%$ \\
& Rata-rata \% Pertumbuhan & $6,93 \%$ \\
\hline \hline
\end{tabular}

Tabel 7.

Rekapitulasi pergerakan pesawat

\begin{tabular}{|c|c|c|c|c|}
\hline Tahun & Internasional & $\begin{array}{c}\text { Persentase } \\
\text { Pertumbuhan }\end{array}$ & $\begin{array}{c}\text { Domestik } \\
\text { \& Lokal }\end{array}$ & $\begin{array}{c}\text { Persentase } \\
\text { Pertumbuhan }\end{array}$ \\
\hline 2009 & 9.855 & - & 84.211 & - \\
\hline 2010 & 9.038 & $-8,29 \%$ & 93.149 & $10,61 \%$ \\
\hline 2011 & 10.316 & $14,14 \%$ & 106.449 & $14,28 \%$ \\
\hline 2012 & 10.452 & $1,32 \%$ & 124.372 & $16,84 \%$ \\
\hline 2013 & 14.183 & $35,70 \%$ & 125.515 & $0,92 \%$ \\
\hline 2014 & 12.796 & $-9,78 \%$ & 123.399 & $-1,69 \%$ \\
\hline 2015 & 12.198 & $-4,67 \%$ & 124.853 & $1,18 \%$ \\
\hline 2016 & 12.265 & $0,55 \%$ & 136.337 & $9,20 \%$ \\
\hline \multicolumn{2}{|c|}{$\begin{array}{c}\text { Rata-rata } \\
\text { Pertumbuhan }\end{array}$} & $4,14 \%$ & & $7,33 \%$ \\
\hline
\end{tabular}

\section{Analisis Kebutuhan Overlay dan Penjadwalan Pemeliharaan}

Analisis kekuatan perkerasan runway dilakukan dengan menggunakan program bantu COMFAA dengan memasukkan data eksisting runway yang didapatkan dari PT. Angkasa Pura I. Pada data eksisting runway dibagi kedalam beberapa segmen yang tiap segmennya akan dilakukan pengecekan kekuatan perkerasan terhadap pesawat pengguna runway. Hasil dari pengecekan tiap segmen dapat dilihat pada tabel berikut ini. Tabel 8.

Rekapitulasi Output COMFAA

\begin{tabular}{ccc|cc|cc}
\hline \multicolumn{5}{c|}{ Segmentasi } & \multicolumn{3}{|c|}{ Ketebalan } & ACN & PCN \\
\hline Segmen & STA & Panjang & Eksisting & Ekuivalen & B-777 & COMFAA \\
\hline 1 & $0+300$ & 300 & 1219 & 1505.8 & 129 & 86 \\
2 & $0+300-0+564$ & 264 & 1219 & 1505.8 & 129 & 86 \\
3 & $0+564-0+820$ & 256 & 1219 & 1505.8 & 129 & 86 \\
4 & $0+820-1+100$ & 280 & 1209 & 1489.8 & 129 & 84 \\
5 & $1+100-1+445.34$ & 345.34 & 1129 & 1361.8 & 129 & 68 \\
6 & $1+445.34-1+700$ & 254.66 & 1209 & 1489.8 & 129 & 84 \\
7 & $1+700-2+178$ & 478 & 1289 & 1617.8 & 129 & 103 \\
8 & $2+178-2+564$ & 386 & 1299 & 1633.8 & 129 & 104 \\
9 & $2+564-2+700$ & 136 & 1299 & 1633.8 & 129 & 104 \\
10 & $2+700-3+000$ & 300 & 1219 & 1505.8 & 129 & 86 \\
\hline \multicolumn{7}{c}{}
\end{tabular}

Dari rekapitulasi diatas, hasil output COMFAA dibandingkan dengan nilai $\mathrm{ACN}$ pesawat jenis Boeing 777 yang telah beroperasi di bandar udara Juanda menunjukkan bahwa nilai PCN yang tersedia masih belum cukup baik. Namun, karena pertumbuhan pergerakan pesawat B777 di bandara Juanda masih terlalu kecil, maka hasil PCN tersebut masih cukup untuk melayani kebutuhan penerbangan. Dari output
COMFAA menunjukkan bahwa beberapa segmen masih memiliki nilai PCN yang lebih besar daripada nilai $\mathrm{ACN}$ untuk pesawat dengan demand tinggi di bandara Juanda Dikarenakan ada beberapa segmen yang masih memliki nilai PCN rendah, maka dilakukan usaha pemeliharaan berupa tindakan overlay. Pemeliharaan overlay yang dilakukan difokuskan untuk menaikkan nilai PCN serta meratakan permukaan perkerasan runway.

Setelah dilakukan pengecekan kekuatan dengan program COMFAA dan diperlukan adanya overlay, maka perlu direncanakan berapa tebal lapisan perkerasan tambahan yang diperlukan. Perencanaan serta penentuan kebutuhan tebal perkerasan dilakukan dengan bantuan program bantu FAARFIELD. Hasil dari output program dapat dilihat pada tabel berikut ini.

Tabel 9.

Rekapitulasi Output FAARFIELD

\begin{tabular}{|c|c|c|c|c|c|}
\hline \multicolumn{5}{|c|}{ Segmentasi } & \multicolumn{2}{|c|}{ Ketebalan Lapisan Permukaan (mm) } & Kebutuhan \\
\hline Segmen & STA & Panjang & Eksisting & Output & Tebal $(\mathrm{cm})$ \\
\hline 1 & $0+300$ & 300 & 127 & 227.2 & 10.02 \\
\hline 2 & $0+300-0+564$ & 264 & 127 & 227.2 & 10.02 \\
\hline 3 & $0+564-0+820$ & 256 & 127 & 227.2 & 10.02 \\
\hline 4 & $0+820-1+100$ & 280 & 127 & 238.6 & 11.16 \\
\hline 5 & $1+100-1+445.34$ & 345.34 & 127 & 330 & 20.3 \\
\hline 6 & $1+445.34-1+700$ & 254.66 & 127 & 238.6 & 11.16 \\
\hline 7 & $1+700-2+178$ & 478 & 127 & 147.2 & 2.02 \\
\hline 8 & $2+178-2+564$ & 386 & 127 & 135.6 & 0.86 \\
\hline 9 & $2+564-2+700$ & 136 & 127 & 135.6 & 0.86 \\
\hline 10 & $2+700-3+000$ & 300 & 127 & 227.2 & 10.02 \\
\hline
\end{tabular}

Dari tabel diatas diketahui bahwa pada segmen 5 memerlukan penambahan tebal yang signifikan. Namun, pada beberapa segmen perkerasan lain telah memenuhi standard kebutuhan tebal yang diperlukan. Untuk upaya pemeliharaan pada kegiatan overlay yang dilakukan pada 2012, direncanakan penambahan tebal perkerasan sesuai dengan tebal tertinggi pada lapisan permukaan eksisting (pemerataan). Pemerataan sesuai dengan lapisan tertinggi ini diperlukan juga untuk menyediakan runway yang rata dan aman untuk kegiatan operasional. Sehingga kebutuhan tebal lapisan penambahan dapat dilihat pada tabel 10 .

Tabel 10 .

Kebutuhan penambahan tebal perkerasan

\begin{tabular}{|c|c|c|c|c|c|c|}
\hline \multicolumn{3}{|c|}{ Segmentasi } & \multicolumn{3}{|c|}{ Ketebalan $(\mathrm{mm})$} & \multirow{2}{*}{\begin{tabular}{|c}
$\begin{array}{c}\text { Ketebalan } \\
(\mathrm{cm})\end{array}$ \\
\end{tabular}} \\
\hline Segmen & STA & Panjang & Eksisting & Rencana & Kebutuhan & \\
\hline 1 & $0+300$ & 300 & 1219 & 1299 & 80 & 8 \\
\hline 2 & $0+300-0+564$ & 264 & 1219 & 1299 & 80 & 8 \\
\hline 3 & $0+564-0+820$ & 256 & 1219 & 1299 & 80 & 8 \\
\hline 4 & $0+820-1+100$ & 280 & 1209 & 1299 & 90 & 9 \\
\hline 5 & $1+100-1+445.34$ & 345.34 & 1129 & 1299 & 170 & 17 \\
\hline 6 & $1+445.34-1+700$ & 254.66 & 1209 & 1299 & 90 & 9 \\
\hline 7 & $1+700-2+178$ & 478 & 1289 & 1299 & 10 & 1 \\
\hline 8 & $2+178-2+564$ & 386 & 1299 & 1299 & 0 & 0 \\
\hline 9 & $2+564-2+700$ & 136 & 1299 & 1299 & 0 & 0 \\
\hline 10 & $2+700-3+000$ & 300 & 1219 & 1299 & 80 & 8 \\
\hline
\end{tabular}

Pada data yang diterima dari pihak bandar udara Juanda diketahui bahwa hingga tahun 2012 kegiatan overlay dilakukan setiap 10 tahun. Dengan adanya pertumbuhan pergerakan yang cukup signifikan, maka dari pihak bandar udara Juanda akan melakukan kegiatan overlay pada 2017 sebagai bentuk pemeliharaan untuk memastikan tercapainya umur rencana. Dari data eksisting yang diterima untuk sisa umur layanan yang mampu dilakukan oleh perkerasan, pada segmen 5 hanya tersisa 
2 tahun masa layan. Sisa umur masa layan setiap segmen pada tahun 2014 dapat dilihat pada tabel.

Tabel 11.

Sisa usia masa layan perkerasan eksisting

\begin{tabular}{|c|c|c|r|}
\hline \multicolumn{3}{|c|}{ Segmentasi } & \multirow{2}{*}{$\begin{array}{c}\text { Umur Sisa } \\
\text { (Tahun) }\end{array}$} \\
\hline Segmen & STA & Panjang & 6 \\
\hline 1 & $0+300$ & 300 & 6 \\
\hline 2 & $0+300-0+564$ & 264 & 6 \\
\hline 3 & $0+564-0+820$ & 256 & 5 \\
\hline 4 & $0+820-1+100$ & 280 & 2 \\
\hline 5 & $1+100-1+445.34$ & 345.34 & 5 \\
\hline 6 & $1+445.34-1+700$ & 254.66 & 16 \\
\hline 7 & $1+700-2+178$ & 478 & 18 \\
\hline 8 & $2+178-2+564$ & 386 & 18 \\
\hline 9 & $2+564-2+700$ & 136 & 6 \\
\hline 10 & $2+700-3+000$ & 300 & \\
\hline
\end{tabular}

Data sisa usia masa layan yang diterima adalah pada tahun 2014 sehingga perencanaan usia rencana dari overlay pada 2012 adalah 20 tahun, jika pada 2017 dilakukan overlay dengan melakukan perataan pada semua segmen maka usia layan dapat ditingkatkan sehingga jadwal pemeliharaan runway didapatkan setiap 5 tahun sekali untuk membantu mencapai usia rencana.

\section{KESIMPULAN}

\section{A. Kesimpulan}

Dari hasil perhitungan dan analisis didapatkan kesimpulan sebagai berikut :

1) Pertumbuhan pergerakan pesawat total rata-rata per tahun sebesar $6.93 \%$. Untuk penerbangan domestik mengalami pertumbuhan pergerakan pesawat rata-rata $7.33 \%$ dan $4.14 \%$ pada penerbangan internasional.

2) Kondisi perkerasan runway di bandar udara Juanda pada sistem peratingan berdasarkan pengamatan visual, masuk dalam kategori rating 3 (fair) dimana dalam rating ini diperlukan tindakan pemeliharaan berupa overlay.

3) Pemeliharaan untuk runway dilakukan dengan perataan berupa overlay dengan ketebalan menyesuaikan dengan tebal perkerasan tertinggi yaitu $1299 \mathrm{~mm}$. Hal ini dapat membantu meningkatkan usia layan khususnya pada segmen 5 .

4) Jadwal untuk pemeliharaan runway direncanakan setiap 20 tahun usia rencana dengan masa pemeliharaan runway setiap 5 tahun sekali.

B. Saran

Beberapa saran yang mungkin dapat dilaksanakan untuk membantu kegiatan pemeliharaan pada perkerasan antara lain:

1) Perlu dilakukan pengecekan dan evaluasi intensif terhadap pertumbuhan pergerakan pesawat karena seiring bertambahnya tahun, demand atau peminat pengguna transportasi udara akan meningkat dan lebih sering dibutuhkan.

2) Perlu dilakukannya pengecekan terhadap kondisi perkerasan runway setiap 1 tahun sekali untuk mengantisipasi tidak sesuainya kondisi lapangan dengan rencana.

Dalam melakukan perbaikan seperti overlay yang membutuhkan persetujuan dana dan urusan birokrasi lainnya, hendaknya sebelum dilakukan penanganan diadakan penilaian kondisi perkerasan kembali agar pihak bandar udara mengetahui pasti bahwa kerusakan dan kondisi perkerasan runway memiliki kondisi yang sama dengan saat dilakukannya penilaian kondisi perkerasan dahulu.

\section{DAFTAR PUSTAKA}

[1] J. I. Airport, "juanda-airport," 2016. [Online]. Available: juandaairport: https://juanda-airport.com/id/berita/index.

[2] J. I. Airport, "juanda-airport," 2016.

[3] F. A. Administration, Advisory Circular 150/5320-17, Airfield Pavement Surface Evaluation and Rating Manuals. Washington D.C.: US Department of Transportation, 2004.

[4] J. P. DIREKTUR, Pedoman Program Pemeliharan Konstruksi Perkerasan Bandar Udara. Jakarta: Direktorat Jenderal Perhubungan Udara, 2015. 